\title{
BRUJAS Y BEATAS EN EL VIRREINATO DEL PERÚ: DESVÍOS DE LA EDUCACIÓN FEMENINA ${ }^{1}$
}

\author{
Marta Ortiz Canseco \\ Universidad Internacional de La Rioja \\ marta.ortiz@unir.net
}

\section{Mujeres e Inquisición en el virreinato del Perú}

$\mathrm{E}$

1 tribunal de la Inquisición en la Ciudad de los Reyes fue fundado en 1569 por Real Cédula de Felipe II, quien ordenó a las autoridades, comenzando por el virrey Francisco de Toledo, que apoyaran las acciones del recién creado tribunal limeño (García de Proodian 1966). Tal y como sucedía en Europa desde el periodo medieval, todos los tribunales represores buscaban «la colaboración entre la Iglesia y el Estado para controlar las ideas sociales subversivas» (Kamen 1992: 15). Hablamos del «Estado» como si fuera algo tangible y físico; cuando apelamos a las «razones de Estado» justificamos toda clase de actos brutales. Sin embargo, el Estado es ideología: el poder fantasmal del gobierno permite disociarlo de las relaciones sociales que lo producen; entendemos el Estado de una manera que deja fuera todas las relaciones sociales y las fuerzas políticas que lo determinan (Silverblatt 2004: 79). Como es sabido, los autos de fe servían para construir un recuerdo indeleble del poder del tribunal sobre la vida y la muerte, pero también propagaban los misterios del Estado, transformando a los magistrados en dioses y a la Inquisición en una fuerza independiente.

Como ha estudiado Bourdieu (2016: 83), es típico del poder dominante hacer que «se reconozca como universal su manera de ser particular». De este modo, los poderes del Estado contribuyen a la «deshistoricización» de su propia historia,

\footnotetext{
1 Este artículo se ha desarrollado dentro del proyecto «Tradición y originalidad en la cultura humanística de Indias. Géneros, paratextos y traducciones en el mundo atlántico (siglos XVIXVII)» (FFI2017-87858-P), I+D de Excelencia del Ministerio de Economía y Competitividad (MINECO), financiado por AEI y FEDER/UE.
}

Edad de Oro, XXXVIII (2019), pp. 329-342, ISSN: 0212-0429 - ISSNe: 2605-3314 
es decir, a hacer creer en la neutralidad de su existencia, para «eternizar» las relaciones de subordinación que favorecen su permanencia. En el caso de la historia occidental, la división sexual constituye una de sus marcas de identidad. Aquello que en la historia «aparece como eterno solo es el producto de un trabajo de eternización que incumbe a unas instituciones (interconectadas) tales como la Familia, la Iglesia, el Estado, la Escuela» (Bourdieu 2016: 8). Cuando hablamos del tribunal de la Inquisición, nos encontramos ante una de las grandes instituciones que, bajo el ala de la Iglesia y el Estado, contribuyeron a la represión de las mujeres en el paso de la Edad Media al Renacimiento y a su silenciamiento en el desarrollo de las incipientes sociedades capitalistas.

Una 'historia de las mujeres' que intente demostrar, aunque sea a pesar suyo, una gran parte de las constantes y las permanencias, está obligada, si quiere ser consecuente, a dejar un espacio, y sin duda el más importante, a la historia de los agentes y de las instituciones que concurren permanentemente a asegurar esas permanencias, Iglesia, Estado, Escuela, etc., y que pueden ser diferentes, a lo largo de las diferentes épocas, en su peso relativo y sus funciones (Bourdieu 2016: 105).

Por esta razón, nos proponemos aquí revisar algunos de los mecanismos de los que se valía el Santo Oficio para contribuir a la represión pública de aquellas mujeres que buscaron encarnar identidades diferentes a las que la sociedad les imponía. Solo una revisión de las prácticas inquisitoriales desde un punto de vista feminista, tal y como viene realizando la crítica Silvia Federici (2010), nos permitirá comprender los modos en que esta institución contribuyó a la «neutralización» de las prácticas patriarcales en relación con la dominación y subordinación de las mujeres. Para ello, en un primer momento comentaremos cuáles fueron los principales delitos de los que se las acusaron; revisaremos después algunos de los textos fundacionales europeos que impulsaron la represión de las mujeres, textos que viajaron a América y configuraron allí parte de la mentalidad patriarcal y colonial; y terminaremos con algunos ejemplos de mujeres represaliadas por el tribunal limeño.

Como afirman Díaz y Quispe (2017), a pesar de su posición subalterna en comparación con los agentes masculinos, las mujeres fueron participantes activos de las sociedades coloniales en América. Estas dos críticas definen los conceptos de «voz»y «texto» como intercambiables. La «Voz» aludiría a la intención y participación de agentes femeninos en la producción de textos escritos por hombres, por ejemplo, en el caso de mujeres juzgadas por la Inquisición, las afroperuanas que dejaron testamentos o la poesía de indígenas. El «texto», por su parte, representa la producción cultural de las mujeres que no ha recibido atención por parte de la crítica, por ejemplo las cartas o artículos en periódicos escritos por mujeres (Díaz y Quispe 2017: 1). En el caso del corpus de documentos inquisitoriales del 
virreinato del Perú, accedemos principalmente a la «voz» de las mujeres juzgadas, dado que ellas no tuvieron la oportunidad de producir textos directamente, o bien los textos que produjeron fueron sistemáticamente destruidos, como es el caso de las miles de páginas que escribió en vida la célebre beata Ángela Carranza y que el tribunal de la Inquisición arrojó a las llamas durante su cautiverio.

El estudio de la hechicería femenina y de la beatería, con sus variadas formas concebidas como manifestaciones culturales femeninas, permitirá apreciar cómo las mujeres fueron protagonistas de la formación de una cultura y de su influencia en la conciencia colectiva. Se pone así en cuestión el estereotipo de mujeres pasivas y confinadas al espacio doméstico, marginales a la formación de una visión del mundo. Al mismo tiempo, los procesos inquisitoriales también guardan valiosas claves para entender el discurso dominante referido al comportamiento de las mujeres y a los mecanismos de control de la sexualidad (Mannarelli 1998: 18).

Debemos prestar una atención particular a los modos en que las mujeres negociaron con la cultura letrada para alcanzar sus objetivos. Estas negociaciones incluían, por ejemplo, su acceso a estrategias retóricas para comunicar sus preocupaciones, así como la aceptación de mediadores como escribanos, notarios y clérigos. Lejos de reducir la autoridad de las mujeres a la presencia de los hombres en esas negociaciones, Díaz y Quispe (2017: 5) proponen analizar la representación de las mujeres en estos textos, además de la historia inherente del lenguaje de las mujeres y de su expresión textual. Para estudiar la producción discursiva de las mujeres, hay que observar cómo se las ingeniaron para dejar sus marcas en el corpus documental.

Si tuviéramos que mencionar una acusación típica del tribunal de la Inquisición contra las mujeres, esta sería la de brujería y hechicería. La imagen de la bruja es producida, a lo largo de la historia occidental, por «los grupos dominantes que, en determinado momento histórico, se vieron amenazados por la existencia y las prácticas de estas mujeres, a tal punto que decidieron exterminarlas» (Mannarelli 1998: 21). Tal y como estudia Mannarelli, en la segunda mitad del siglo XVII comparecieron ante el tribunal limeño ciento ochenta y cuatro personas, de las cuales ciento veinte eran hombres y sesenta y cuatro mujeres. De ellas, cuarenta y nueve fueron acusadas de hechiceras, frente a solo once hombres que comparecieron bajo el mismo cargo. Por estas cifras podemos deducir que, si bien la caza de brujas no constituyó un fenómeno masivo, sí sucedió principalmente en ámbitos urbanos y fue llevada a cabo contra las mujeres. Dado que el traslado de los acusados era costoso y las zonas más alejadas de su radio de acción estaban menos vigiladas, el control inquisitorial fue más eficaz en la zona urbana de Lima y en áreas cercanas. Además, la mayor o menor afluencia de persecución de brujas dependía de conflictos sociales concretos en cada comunidad. Se trata de un 
hecho social, no religioso, puesto que las mujeres fueron acusadas en momentos históricos específicos y no continuamente en la misma medida. Por otra parte, hay que tener en cuenta que «la población indígena estaba fuera del control de la Inquisición y los casos de hechicería andina eran juzgados bajo criterios específicos por un tribunal de extirpación de idolatrías» (Mannarelli 1998: 25).

En efecto, la especificidad que encontraremos en procesos de la Inquisición limeña en relación con el tribunal peninsular es la ambigua vinculación que existe entre la lucha contra la herejía y la extirpación de idolatrías. Al comienzo del proceso evangelizador, «los eclesiásticos consideraron que las religiones prehispánicas eran resultado de la influencia diabólica sobre la población india», de ahí que las caracterizaran como religiones falsas y las denominaran «idolatrías» (Chocano 2000: 130). El primer objetivo del clero fue desplazar estas religiones y sustituirlas por los preceptos cristianos, si bien fueron muy conscientes de la dificultad que conllevaba combatir la permanencia de muchos de los cultos indígenas locales. Durante el gobierno del virrey Francisco de Toledo (1569-1581) se produjo un giro en la historia de la extirpación de idolatrías: bajo su mandato se empezó a considerar «la conversión de los indios y la liquidación de la religión peruana» como un «asunto de Estado», lo que permitió al virrey, por otra parte, subordinar las labores de la Iglesia al Estado (Duviols 1977: 145). No es casualidad que fuera justamente bajo el mandato de Toledo cuando se estableció el tribunal de la Inquisición limeño.

En efecto, en el Perú del siglo XVII, las campañas de extirpación de idolatrías tuvieron especial relevancia y contaron con el apoyo de autoridades tanto civiles como eclesiásticas. Parece que, igual que con los procesos de caza de brujas, aunque las prácticas paganas existieran de manera constante, solo unas circunstancias sociales determinadas empujaban a la institución eclesiástica a emprender estas campañas puntuales. Chocano (2000) señala, por ejemplo, la existencia de denuncias contra los abusos de autoridad por parte de los curas locales, extorsiones económicas o su afán por acumular poder político. En 1610 se había creado el cargo especial de «visitador de idolatrías, un sacerdote que tenía la misión de ir a los distintos pueblos indios y recoger denuncias contra los presuntos idólatras y hechiceros para luego someterlos a un interrogatorio, juzgarlos y sentenciarlos» (Chocano 2000: 132). De ahí que, en el contexto peruano, los casos de idolatría no los llevara el tribunal de la Inquisición — bajo cuya jurisdicción no entraban los juicios a la población indígena-, sino las comisiones de extirpación de idolatrías, que ejercieron su poder principalmente en las zonas rurales. Esta es la causa de que, en el conjunto de mujeres que encontraremos juzgadas por la Inquisición limeña, estas pertenezcan en su mayor parte a sectores sociales deprimidos, no necesariamente vinculados a un grupo étnico específico, sino a las clases sociales urbanas más bajas. Como afirma Mannarelli, muchas de las acusadas no tenían 
oficio o eran esclavas, prostitutas, cocineras, vendedoras ambulantes, etc. De manera que «este fenómeno tuvo un signo de clase», pero no de etnia (Mannarelli 1998: 30).

A continuación veremos cuáles eran los patrones que regían el comportamiento de las mujeres de los siglos XVI y XVII, cómo se establecieron en el Nuevo Mundo y de qué maneras el desvío con respecto a estos patrones podía producir la persecución inquisitorial y su encierro.

\section{La educación SeXual de las mujeres en el Nuevo Mundo}

Es un hecho que la presencia de las mujeres en la corte inquisitorial se asociaba a delitos con implicaciones sexuales, es decir, a un uso demasiado libre de sus propios cuerpos:

En una sociedad como la colonial, la sola presencia de las mujeres en los espacios públicos, tenía implicancias deshonrosas. Su vulnerabilidad en lugares como las cortes estuvo fuertemente asociada a la exposición de su vida sexual. La confirmación de un comportamiento sexual dudoso rebajaba el crédito de la palabra femenina a un nivel incluso menor del que al inicio tenía - en comparación con los hombres - solo por el hecho de ser mujer. Esta situación nos remite a la naturaleza de la organización de la sociedad colonial, en la medida en que el control de la sexualidad femenina fue un componente esencial de su orden (Mannarelli 1998: 17).

Sin embargo, esto no es algo privativo de las colonias, sino que se trata de ordenamientos sociales exportados por Europa al Nuevo Mundo. En la estela de los coloquios escritos por Erasmo, el intelectual Juan Luis Vives había inaugurado en el pensamiento hispano la escritura de tratados centrados en la educación femenina con su famoso texto Instrucción de la mujer cristiana (1523). En esta obra, «apela a la analogía antropomórfica, cabeza-Estado, para ilustrar la posición de autoridad que debía ocupar el marido en el matrimonio» (Rivera 2002: 16). Tanto en época clásica y medieval, como en época renacentista, se solía comparar al rey con la cabeza del Estado, y al pueblo con el cuerpo, regido por la cabeza. Esta metáfora es trasladada al ámbito del hogar, en el que el hombre se convierte en el rey de la casa, de manera que la mujer no solo queda relegada al espacio doméstico, sino que se convierte además en súbdita de su marido. El objetivo de este tipo de tratados era el de construir la identidad de las mujeres, otorgándoles un papel en el hogar que era inapelable y que debía ser completamente asumido por ellas.

La educación de las mujeres constituía una preocupación capital para los humanistas cristianos del siglo XVI y su formación para el matrimonio dio lugar a «una verdadera corriente de pensamiento en la que se incluyeron la práctica 
totalidad de filósofos, moralistas y pensadores de la época, clérigos y seglares, pertenecieran o no a las filas erasmianas» (Romero 1998: 151). Estos textos muestran la importancia que, tras el Concilio de Trento, se otorgó «a la divulgación de modelos ortodoxos de comportamiento social y privado, especialmente para las mujeres» (Millán 2017: 124). Por norma general, estos textos trataban temas como la división entre el espacio público (del hombre) y el privado (de la mujer); las virtudes que debían caracterizar al género femenino, como el silencio, la obediencia o la docilidad; la sistematización de los estados de las mujeres (doncellas, casadas, viudas y monjas), así como el comportamiento que les correspondía en cada uno de esos estados; los atuendos que debían llevar para evitar la lujuria de los hombres, para no despertar la curiosidad, la codicia o la ambición, etc.

De este modo, durante el Renacimiento irá consolidándose la separación entre la esfera pública y la privada, así como el rol que cada género debía tomar para el buen funcionamiento de la incipiente sociedad capitalista, con todo lo que ello ha supuesto histórica, ideológica y políticamente hasta nuestros días. Las mujeres «quedaban sometidas al padre, marido o la regla del convento, y aquellas que no se ajustaran en ninguno de estos papeles vivían de manera precaria y sobre todo siempre indefensas» (Sánchez 1991: 51). De hecho, la mayoría de las mujeres acusadas de brujas eran solteras o viudas, es decir, dependían de su propio trabajo y no de la estabilidad económica de un marido. «Estas mujeres estaban al margen de la estructura familiar y, por lo tanto, de la tutela masculina» (Mannarelli 1998: 31), algo muy peligroso en la sociedad renacentista, tanto europea como colonial.

Cabe destacar que el tema de la sexualidad era uno de los más mencionados en las acusaciones a mujeres por brujería, a ambos lados del océano. En el virreinato peruano, de hecho, apenas hay casos de hechiceras ancianas. Si el matrimonio se consideraba como «una forma de ordenar la sexualidad» (Morant 2002: 20), veremos que precisamente todos los pecados relacionados con el uso del cuerpo serán los más castigados en las mujeres: tanto una sexualidad demasiado libre, como el comer mucho y con gusto, los modos deshonestos de vestirse, la manera de caminar por la calle, etc. A la represión colectiva de estos hábitos contribuyeron los manuales de educación de mujeres que venimos mencionando. Si bien el famoso manual para inquisidores, el Malleus maleficarum (1487), fue uno de los grandes pilares sobre los que se sustentaron las acusaciones y condenas del Santo Oficio, no debemos olvidar la enorme importancia que tuvieron otros manuales de educación de las mujeres que empaparon la mentalidad colonial.

Viajaron muy precozmente a América libros como la Instrucción de la mujer cristiana (1523), de Vives; el Relox de príncipes (1529), de Antonio de Guevara, cuyo segundo libro está dedicado a «la manera que los príncipes y graves señores se han de haber con sus mujeres y de cómo han de criar a sus hijos» (1532: 70r); los Coloquios matrimoniales (1550), de Pedro de Luján; las Reglas de bien 
vivir muy provechosas (y aun necesarias) a la república cristiana (1552), de Antonio de Espinosa; La perfecta casada (1583), de fray Luis de León; el Tratado del gobierno de la familia y estado de las viudas y doncellas (1597), de Gaspar de Astete; o el Libro intitulado vida política de todos los estados de mujeres (1599), de Juan de la Cerda. Pero quizá el que más se repite en los inventarios de libros llegados al Nuevo Mundo es el célebre Examen de ingenios (1575), de Juan Huarte de San Juan, quien, apoyándose en las teorías de Aristóteles, Hipócrates y Galeno, pretende establecer la superioridad racional del hombre sobre la mujer a partir de sus características físicas. En esta misma estela, muchísimos autores del Renacimiento quisieron demostrar la inferioridad de las mujeres, bien con argumentos sobre su inteligencia racional, bien sobre sus rasgos físicos, y establecieron la necesidad por parte del hombre de controlarla, dominarla y guiarla en su comportamiento.

Estas teorías constituyen la base sobre la que se construye el miedo hacia las mujeres demasiado libres o dueñas de su espacio y de su cuerpo, aquellas a las que, en definitiva, se terminaba por acusar de brujas o de «ilusas». De hecho, «las hechiceras fueron percibidas por las autoridades y por el pueblo en general como personas peligrosas y poderosas, capaces de controlar a los hombres y de atraerlos según su voluntad más allá del propio consentimiento de estos» (Mannarelli 1998: 40). El hecho de que las mujeres recurrieran a la hechicería para cambiar sus relaciones con los hombres nos da una idea de las limitaciones que sufrían en el ambiente social en el que vivían. Ellas estaban cuestionando a la autoridad, en la medida en que no solo no se conformaban con el rol que se les asignaba como mujeres, sino que pretendían también cambiar el de los hombres: los querían más pacíficos, dóciles, manejables. Este deseo no deja de revelar la violencia cotidiana a la que se enfrentaban y el modo como su postura desafiaba el rol que las autoridades asignaba a las mujeres como obedientes y recatadas.

Con todo, de manera paralela a las prácticas de hechicería, hubo mujeres que pudieron canalizar sus deseos de libertad bajo el paraguas de la devoción religiosa. Algunas de ellas lograron transformarse en grandes y veneradas santas (como es el caso de la célebre santa Rosa de Lima), pero otras no tuvieron tanta suerte y cayeron en la desgracia del juicio inquisitorial, como muchas de las discípulas de la propia santa Rosa, como Ángela de Carranza o María Jacinta de Montoya, por solo citar a algunas. A continuación revisaremos el modo en que estas mujeres pecaron por no ajustarse lo suficiente a las líneas de comportamiento femenino marcadas por los grandes intelectuales renacentistas. 


\section{Disidencias: los placeres carnales de Ángela de Carranza}

Tomar los hábitos de monja se había convertido en una de las pocas vías de integración social para aquellas mujeres que se negaban a casarse o que no se lo podían permitir por motivos económicos. Como afirma Sánchez (1993: 268), «en los conventos las mujeres adquirían un status social fuera de la tutela directa del hombre». Sin embargo, también para entrar en un convento se requería una mínima solvencia económica, pues estos espacios reproducían la realidad exterior, respetando escrupulosamente la clase social: «Las ricas seguían siendo ricas y las pobres muy pobres» (Sánchez 1993: 270). De este modo, las mujeres que no se podían permitir entrar en un convento muchas veces optaron por convertirse en «beatas».

En un principio, se consideraba como beatas a las mujeres devotas y honradas que no respondían a ninguno de los roles reservados a la mujer: no eran ni esposas, ni madres, ni religiosas, ni prostitutas. Aspiraban a la perfección cristiana a través de una devoción solitaria y humilde, y vivían de la caridad y generosidad de la gente. Este fenómeno «adquiere grandes dimensiones en la Europa de la Contrarreforma, reflejando tanto aspiraciones religiosas como las dificultades crecientes de las mujeres sin dote suficiente para entrar en los conventos» (Gilhem 1981: 184). Lo más llamativo de las beatas era la aparente libertad de que disfrutaban: no vivían encerradas, no dependían de ningún hombre, su relación con la divinidad era personal, no necesariamente mediada por las autoridades eclesiásticas, etc. Por esa razón, este tipo de vida de algunas mujeres se conoció como la «tercera vía», puesto que se trataba de un tercer estado que no respondía ni al matrimonio ni a la vida conventual. Esta tercera vía «implicaba un celibato voluntario y resolvía la dicotomía entre la vida activa y la contemplativa, pues las beatas podían pertenecer a las dos» (Rice 2018: 195).

La proliferación de las beatas se relaciona de manera directa, en palabras de Sánchez (1993: 274), «con la explosión de religiosidad que caracteriza la época». Como es evidente, las autoridades inquisitoriales no tardaron en advertir de los peligros que este tipo de espiritualidad intimista podía acarrear dentro del mundo religioso de la Contrarreforma. Muchas mujeres que habían sido consideradas casi santas por la sociedad que las rodeaba, como ejemplos de virtud para infinidad de devotos, acabaron siendo juzgadas porque sus relaciones con Dios rondaban un terreno peligroso entre la devoción y la herejía. Se trataba, a fin de cuentas, de «una vida religiosa femenina sin supervisión» (Rice 2018: 196), esto es, sin supervisión masculina. Para las mujeres con un comportamiento particularmente devoto, se requerían ciertos elementos adicionales, entre los que destacaban la humildad y la obediencia a las autoridades religiosas masculinas; es decir, en el caso del género femenino, un comportamiento correcto era más deseable que cualquier milagro (Schlau 2017: 21). 
El ejemplo de Ángela Carranza puede ilustrar bien este recorrido. Nacida en Córdoba de Tucumán cerca de 1642, esta beata agustina pasó a Lima aproximadamente en el año 1665, donde comenzó a llamarse a sí misma Ángela de Dios, por la estrecha relación que parecía mantener con la divinidad.

Tanto en su patria como en el Perú supo conservar reputación de casta y honrada, sin que alanzasen a mancillarla las calumnias de sus enemigos. Dos años después de estar en Lima corrió la voz de que recibía favores y revelaciones del cielo, y en 1673 empezó a escribir estas, aumentando así entre el vulgo su fama de santa e inspirada. Atribuíanla el poder de practicar milagros y creían las almas candorosas que curaba toda especie de males por medio de cuentas o globulillos de cristal (Palma 1863: 21-22).

En 1689 tuvo su primera audiencia ante el tribunal de la Inquisición y permaneció encerrada, siendo interrogada y torturada durante seis años, hasta que, en 1694, se celebró el auto de fe en que sale como penitente para abjurar de vehementi, se le condena a permanecer recluida en un monasterio durante cuatro años, a ayunar y se le prohíbe escribir. Esta beata encarna bien el modelo de mujer que, por salirse demasiado de los moldes asignados al género femenino, sufrió las represalias de las autoridades eclesiásticas. Resulta sintomático que la propia Ángela justificara su conexión con lo divino por «el estado de la niñez» que le había conferido Dios; solo la inocencia infantil (según sus escritos, Ángela no tenía más de tres años) «explicaría parte de la importante carga lúdica presente en sus escritos» (Mannarellli 1998: 65).

Del mismo modo, Ángela de Carranza demuestra una relación muy libre con su propio cuerpo y son célebres los episodios en que se vio a la beata desnuda en espacios públicos. En una sociedad en la que se legislaba incluso cómo debía vestirse la mujer, esta beata desafía peligrosamente la privacidad de la desnudez:

El pudor, pues, es ajeno a la santa; su cuerpo como su poder es público. Ella está más allá de la mirada de los comunes mortales. Su condición de santidad, en plena sociedad jerárquica, la eleva a tal grado que lo inferior no existe; los ojos de sus inferiores no la perturban; no ejercen ningún control desde fuera (Mannarellli 1998: 71).

Pero uno de los elementos que más heterodoxo podía considerarse en el comportamiento femenino fue el propio acto de escribir. Como explica Schlau (2017), cuando un texto se consideraba ambiguo contra la doctrina religiosa, la respuesta más usual era quemarlo. Del mismo modo que se quemaban los cuerpos o las efigies en los autos de fe inquisitoriales, también se echaban a la hoguera todo tipo de libros, cuadernos o panfletos. Pocas mujeres tenían acceso a lo que se 
consideraba la escritura oficial y, cuando escribieron textos que no encajaban en los géneros oficiales, como en el caso de Carranza, lo más común era que sus escritos acabaran siendo destruidos. Sin embargo, como comentábamos al comienzo del texto, es importante rescatar de los testimonios recogidos por hombres la voz de estas mujeres acusadas y reprimidas.

El único documento conservado en torno al caso de Carranza es la Relación que el doctor Francisco Valera, de la Inquisición limeña, escribió para el Consejo Supremo del Santo Oficio en España. Se trata de un documento muy bien organizado, en 31 capítulos, con índice, cuyo propósito era informar a la Suprema de que los procesos se realizaban correctamente. El relato se compone de transcripciones del proceso, con las declaraciones de testigos, audiencias, etc., así como de algunos fragmentos textuales de los 7.500 folios que Ángela había escrito y que fueron confiscados y quemados. En definitiva, «resulta casi imposible separar la intervención clerical de los documentos de origen» (Schlau 2008: 12).

Como estudia Rice (2018), no estamos ante un caso aislado, sino que encontramos un modelo social de «construcción» de las beatas. Se trata de mujeres que comenzaban siendo bien valoradas por la sociedad, incluso reverenciadas y respetadas, pero que en un momento dado empezaban a «exagerar y acercarse más y más al precipicio de la herejía gracias a la retroalimentación positiva que reciben» por parte de sus coetáneos religiosos (Rice 2018: 197). El caso que Rice estudia es el de la beata novohispana Marina de San Miguel, quien, como Ángela Carranza, tuvo también problemas con la Inquisición mexicana en el siglo XVII.

A muchas de estas mujeres se les acusó de ilusas o iludentes, una acusación forjada para las mujeres, puesto que se consideraba que ellas, por naturaleza, estaban más inclinadas a la vanidad, a la tentación y a la mentira. De ahí que se buscaran y castigaran con mayor dureza los pecados relacionados con placeres carnales, como el ya aludido de la desnudez o lujuria, pero también el de la gula:

según la ideología de la época, la mujer estaba más asociada que el hombre con los tres enemigos principales de la Iglesia: el mundo, el diablo y la carne. El que ella [Ángela Carranza] comiera demasiado se asoció con todos sus otros pecados, incluyendo un supuesto pacto con el demonio, cargo que siempre aparecía en casos de una mujer acusada de ilusa, pero que se aplicaba aun más por la acusación de gula. Comer demasiado simbólicamente enfatizaba toda la mitología e ideología en torno al hambre «insaciable» de la mujer, empezando con Eva, por todo lo material (Schlau 2008: 15).

De hecho, el castigo ejemplar que se le da a Carranza es el del encierro, para evitar su exposición pública; el del ayuno, para eludir la gula; y se le prohíbe escribir, para evitar la difusión de sus ideas. La locura de las beatas era peligrosa porque había quienes las escuchaban; lo que los inquisidores quieren reprimir es 
el poder popular que se atribuía a estas mujeres (Guilhem 1981). En una sociedad que dependía del mundo sobrenatural, la experiencia mística de ciertas mujeres «las transformaba en intermediarias con el mundo sobrenatural e intérpretes de la divinidad, un rango que hubiera sido impensable para su destino de mujer. Su relación con Dios se transforma en un factor de poder y una vía de expresión» (Sánchez 1993: 265).

Para revisar este tipo de procesos conviene finalmente que nos planteemos el modo en que los manuales para inquisidores y las lecturas que estos realizaban sobre la educación de las mujeres funcionaron como resortes de creación de la idea de la bruja y la beata. No son las mujeres demasiado libres quienes se salen de unos parámetros establecidos, sino que estos parámetros se establecen en relación con las actitudes demasiado libres de las mujeres que no encajaban en la construcción de las sociedades del Renacimiento. «La alegoría de las brujas no proviene del universo popular, aunque en muchos aspectos confluya; más bien es un producto del imaginario de los inquisidores al que el acusado se quiebra por las presiones del interrogatorio» (Sánchez 1991: 36). Son precisamente la ideología del Malleus y las demás lecturas de los inquisidores las que crean una idea de la bruja y de las hechicerías, y no al revés. El imaginario de jueces, consultores, comisarios, fiscales y familiares no se alejaba de la superstición que invadía la cultura popular. Es a partir del intento por ordenar esa cultura como se establecen los límites de la libertad social, y específicamente de la libertad de las mujeres.

En definitiva, ellas son acusadas de brujas y beatas porque ambas figuras desafían el orden social necesario para la construcción de las comunidades precapitalistas. Los intelectuales europeos difundieron las ideas sobre la inferioridad femenina para que las mujeres permanecieran encerradas en el ámbito privado y fueran los hombres quienes construyeran el espacio público a partir de los parámetros de su propia identidad. Estas ideas se extendieron por América y se erigen como base de las sociedades coloniales, donde mujeres como Ángela Carranza, que se acercaron demasiado al límite de sus libertades, fueron represaliadas por los tribunales específicos para ello. 


\section{BIBLIOGRAFÍA}

Bourdieu, Pierre (2016 [1998]). La dominación masculina. Barcelona: Anagrama.

Chocano, Magdalena (2000). La América colonial (1492-1763). Cultura y vida cotidiana. Madrid: Síntesis.

DíAz, Mónica y Rocío Quispe-Agnoli (2017). «Introduction. Uncovering Women’s Colonial Archive». En Mónica Díaz y Rocío Quispe-Agnoli (eds.), Women’s Negotiations and Textual Agency in Latin America, 1500-1799. New York: Routledge, pp. 1-15.

Duviols, Pierre (1977). La destrucción de las religiones andinas (durante la conquista y la colonia). Ciudad de México: Universidad Nacional Autónoma de México.

Federici, Silvia (2010). Calibán y la bruja. Mujeres, cuerpo y acumulación originaria. Madrid: Traficantes de Sueños.

García de Proodian, Lucía (1966). Los judios en América: sus actividades en los virreinatos de Nueva Castilla y Nueva Granada, s. XVII. Madrid: Centro Superior de Investigaciones Científicas.

Guevara, Antonio de (1532 [1529]). Relox de príncipes. Sevilla: Juan Cromberger.

Guilhem, Claire (1981). «La Inquisición y la devaluación del verbo femenino». En Bartolomé Benassar (ed.), Inquisición española: poder político y control social. Barcelona: Crítica, pp. 171-207.

Kamen, Henry (1992). «Cómo fue la Inquisición: naturaleza del Tribunal y contexto histórico». Revista de la Inquisición, 2, pp. 11-22.

Mannarelli, María Emma (1998). Hechiceras, beatas y expósitas. Mujeres y poder inquisitorial en Lima. Lima: Congreso del Perú.

Millán GonzÁlez, Silvia C. (2017). «Amazonas y lecturas de mujeres, entre la ficción y la moralidad: de la Silva de Mexía al Silves de la Selva y los Coloquios matrimoniales de Luján». Tirant, 20, pp. 119-146.

Morant, Isabel (2002). Discursos de la vida buena. Matrimonio, mujer y sexualidad en la literatura humanista. Madrid: Cátedra.

Palma, Ricardo (1863). Anales de la Inquisición de Lima. Estudio histórico. Lima: Tipografía de Aurelio Alfaro.

Rice, Robin Ann (2018). «Chinas, milagreras, negras y beatas: ejemplos de la vida cotidiana religiosa ante la Inquisición de México en los siglos XVI-XVII». En María Jesús Zamora Calvo (ed.), Mujeres quebradas. La Inquisición y su violencia hacia la heterodoxia en Nueva España. Madrid/Frankfurt am Main: Iberoamericana/ Vervuert.

Rivera, Olga (2002). «La 'natural condición de la mujer' en la retórica de Deberes del marido». Hispanic Journal, 23/2, pp. 9-19.

Romero TABAREs, María Isabel (1998). La mujer casada y la amazona. Un modelo femenino renacentista en la obra de Pedro de Luján. Sevilla: Universidad de Sevilla.

SÁnchez, Ana (1993). "Ángela Carranza, alias Ángela de Dios. Santidad y poder en la sociedad virreinal peruana (s. XVII)». En Henrique Urbano y Gabriela Ramos 
(comps.), Catolicismo y extirpación de idolatrías, siglos XVI-XVII. Cusco: Centro de Estudios Regionales Andinos Bartolomé de Las Casas, pp. 263-292.

SÁnCHEZ, Ana (1991). «Mentalidad popular frente a ideología oficial: el Santo Oficio en Lima y los casos de hechicería (siglo XVII)». En Henrique Urbano (comp.), Poder y violencia en los Andes. Cusco: Centro de Estudios Regionales Andinos Bartolomé de Las Casas, pp. 33-52.

Schlau, Stacey (2017). «Divine aspirations. Beatas, writing, and the Inquisition in late seventeeth-century Lima». En Mónica Díaz y Rocío Quispe-Agnoli (eds.), Women's Negotiations and Textual Agency in Latin America, 1500-1799. New York: Routledge, pp. 19-38.

Schlau, Stacey (2008). «El cuerpo femenino y la Inquisición colonial: dos casos ejemplares». Prohal Monográfico. Revista Electrónica del Programa de Historia de América Latina, I/1, pp. 1-21 <http://www.filo.uba.ar/contenidos/investigacion/ institutos/ravignani/prohal/dossierhere.html> [Consulta: 02/03/2019].

Silverblatt, Irene (2004). Modern Inquisitions: Peru and the Colonial Origins of the Civilized World. Duke: Duke University Press, Durham and London.

VIVES, Juan Luis (1994 [1523]). La formación de la mujer cristiana. Valencia: Ajuntament de València.

Recibido: 30/04/2019

Aceptado: 20/06/2019 
BRUjas y beatas en el VirReinato del Perú: DESVÍOS DE LA EDUCACIÓN FEMENINA

RESUMEN: En este texto comenzaremos ofreciendo una posible metodología de análisis de discurso de las mujeres como «agentes» en el archivo colonial y propondremos rescatar sus voces no solo como autoras del discurso, sino también como colaboradoras de los hombres que transcribieron sus voces. A partir de este silenciamiento en el archivo y del posible rescate de su voz, analizaremos los modos en que la acusación inquisitorial contra las mujeres se centró principalmente en las brujas y las beatas, mujeres que no encajaban en el modelo de perfección femenina que los intelectuales renacentistas quisieron imponer. La metrópoli exportó a la colonia el discurso de dominación de las mujeres a partir del control de su sexualidad y de su aparición en espacios públicos, de manera que terminaremos el texto ofreciendo una serie de claves ideológicas que se transmiten del discurso europeo al americano y que pueblan las cabezas de inquisidores y civiles en esa «guerra contra las mujeres» que tuvo lugar en los albores del capitalismo al comienzo de la Edad Moderna.

Palabras Clave: Inquisición, Lima, mujeres, beatas, Ángela Carranza, siglo XVII.

\section{WitCHES AND BEATAS IN THE VICEROYALTY OF PERU: DEVIATIONS IN FEMALE EDUCATION}

ABSTRACT: This text aims to offer a methodological analysis for women's discourse as "agents» in the colonial archive. We will try to rescue their voices not only as authors, but also as collaborators of the discourses written by men. Based on their apparent silence in the archive and the possible analysis of their voices, we will focus on how the inquisitorial attacks against women were concentrated in witches and beatas, women who didn't fit in the female perfection's models established by the European intelectuals. The colonies inherited the discourse of female domination based on the control of their sexuality and their appearance in public spaces. Finally, we will search some ideological keys that will led us to understand how the European discourse is transferred to the construction of the American colonies in the context of that «war against women» which took place at the beginning of the Early Modern period.

Keywords: Inquisition, Lima, women, Beatas, Ángela Carranza, $17^{\text {th }}$ century. 